\title{
MUSIC AND DANCE AS A COALITION SIGNALING SYSTEM
}

\author{
Edward H. Hagen \\ Institute for Theoretical Biology, Humboldt University, Berlin \\ and \\ Gregory A. Bryant \\ University of California, Santa Cruz
}

\begin{abstract}
Evidence suggests that humans might have neurological specializations for music processing, but a compelling adaptationist account of music and dance is lacking. The sexual selection hypothesis cannot easily account for the widespread performance of music and dance in groups (especially synchronized performances), and the social bonding hypothesis has severe theoretical difficulties. Humans are unique among the primates in their ability to form cooperative alliances between groups in the absence of consanguineal ties. We propose that this unique form of social organization is predicated on music and dance. Music and dance may have evolved as a coalition signaling system that could, among other things, credibly communicate coalition quality, thus permitting meaningful cooperative relationships between groups. This capability may have evolved from coordinated territorial defense signals that are common in many social species, including chimpanzees. We present a study in which manipulation of music synchrony significantly altered subjects' perceptions of music quality, and in which subjects' perceptions of music quality were correlated with their perceptions of coalition quality, supporting our hypothesis. Our hypothesis also has implications for the evolution of psychological mechanisms underlying cultural production in other domains such as food
\end{abstract}

Received October 19, 2001; accepted January 2, 2002; revised version received June 18, 2002.

Address all correspondence to Edward H. Hagen, Institute for Theoretical Biology, Humboldt-Universität zu Berlin, Invalidenstraße 43, 10115 Berlin, Germany. Email: e.hagen@ biologie.hu-berlin.de

Copyright 2003 by Walter de Gruyter, Inc., New York

Human Nature, Vol. 14, No. 1, pp. 21-51.

$1045-6767 / 03 / \$ 1.00+.10$ 
preparation, clothing and body decoration, storytelling and ritual, and tools and other artifacts.
KEY WORDS: Biomusicology; Coalitions; Dance; Music; Evolutionary Psychology; Honest signaling

Champions of the National Endowment for the Arts contrast the relatively large outlays for military music [\$168 million] with the $\$ 98$ million that a House-Senate conference committee approved for endowment spending on all the nation's arts.

-A New York Times article on the 76 military bands funded by the U.S. Department of Defense (J. Miller 1997)

Numerous studies indicate that the human brain might contain neural specializations for processing music (e.g., Ayotte et al. 2002; Johnsrude et al. 2000; Peretz 1996; Peretz and Morais 1993; Perry et al. 1999). This suggests that there may be psychological adaptations for producing and processing this important component of culture. If so, what function or functions did music serve in ancestral human environments? A variety of possible functions has been proposed, the most prominent being that music either promoted "social cohesion" (e.g., Roederer 1984) or signaled mate quality (e.g., Darwin 1871; Miller 2000a, 2000b; Werner and Todd 1997).

We propose that music and dance served, at least in part, as a coalition signaling system. Humans are nearly unique among primates (and, indeed, most social mammals) in that groups form cooperative relationships with other groups. Among the approximately 200 species of nonhuman primates, only hamadryas baboons are known to form cooperative alliances at the group level (Cheney 1987). Hamadryas social organization, however, is strictly hierarchical and kin-based, much like a segmentary lineage system. Humans are apparently unique in their ability to form close, highly cooperative intergroup relationships in the absence of consanguineal ties. In the ethnographic record, the modal pattern is one of male kin forming alliances with other groups of male kin, usually via an exchange of females. Intergroup cooperation is a foundation of the complex, region-wide social structures that characterize humans. As Rodseth et al. (1991:236) put it, "the breakthrough in human social organization ... is intergroup affinity" (emphasis in the original). We believe this breakthrough may have depended critically on music and dance.

The evolution of inter-individual cooperation among non-kin faces a number of well-recognized problems, including individual recognition, the ability to remember past interactions, and the ability to detect cheating 
(e.g., Cosmides 1989). For the evolution of intergroup cooperation, these problems are multiplied. How, for example, does one identify a "group"? That is, how does one determine that large numbers of individuals are willing and able to coordinate their actions to achieve mutually beneficial goals? A mere aggregation of individuals is not, in itself, a coalition. We propose that music and dance solved at least one crucial problem of intergroup cooperation: the credible signaling of coalition quality, including the very existence of a coalition.

\section{PROBLEMS WITH EXISTING THEORIES}

\section{Sexual Selection}

Darwin was the first to propose that music and dance might have evolved as courtship displays. Subsequently, a number of researchers have put forward similar ideas for both humans and other animals (e.g., Catchpole and Slater 1995; Miller 2000a, 2000b), and there is support for it in the ethnographic record. For example:

Mokadayu, of Okopukopu, was a famous [Trobriands] singer. Like all of his profession he was no less renowned for his success with the ladies. "For," say the natives, "the throat is a long passage like the wilu (vulva), and the two attract each other." "A man who has a beautiful voice will like women very much and they will like him" (Malinowski 1925:203; quoted in Merriam 1964:134).

Denig, who lived among the Assiniboin and other Plains groups of the Upper Missouri during the 1850s, similarly wrote:

[S]inging is a very common amusement for the young men at nights, principally to attract the attention of the females, and often intended as signals for secret assignations (Denig 1930:618).

Further, low fluctuating asymmetry is associated with an attractive voice in humans (Hughes et al. 2002). Although sexual selection may provide a partial account of human musical abilities, we feel it is unlikely that it can provide a complete account for the following reasons:

1. In small-scale societies, music and dance are frequently performed during activities like war and politics where time and effort diverted to mating signals could have imposed significant fitness costs in the environment of evolutionary adaptedness (EEA).

2. Humans commonly perform music and dance in groups. The sexual selection hypothesis, which posits that individuals have been 
selected to outcompete their rivals for mates, offers no compelling account of this characteristic feature of music and dance.

3. Rhythm, an important feature of human music that plausibly functions to synchronize musical and dance performances by groups, is not found in the vocalizations of any other primate, including the 26 species that sing (Geissmann 2000). As Denig described the ceremonial songs and dances of the Assiniboin:

The modulations are bold and wild, by no means discordant or disagreeable, and they are remarkable for keeping very exact time either with the voice, drums, or feet ... (Denig 1930:617).

The sexual selection hypothesis offers no account of this important and unique feature of human music.

4. Musically talented males in many societies are subsidized with gifts or payments for singing and are called upon by group leaders to compose songs for the group and/or perform for visitors (e.g., Merriam 1964:123-133); this behavior is difficult to reconcile with the sexual selection hypothesis, although it is quite consistent with the coalition quality advertisement hypothesis to be proposed here. ${ }^{1}$

5. Heterosexuals of all ages and musical skill-levels enjoy, and are strongly attracted to, musical groups of the same sex (e.g., all-male rock groups like Led Zeppelin have millions of male fans ranging from pre-teens to accomplished adult musicians).

6. In the one study we found that evaluated vocal quality specifically as a component of mate value, males ranked "voice" second-to-last of fifteen traits, and females ranked it last (Daniel et al. 1985). Further, the male ranking was significantly higher than the female ranking, precisely the opposite of what the sexual selection hypothesis predicts.

Proponents of the sexual selection hypothesis have offered two responses to objection (2) above. Merker (2000) argues that synchronous chorusing by hominid males would have increased signal amplitude, allowing a group to "extend its geographical reach beyond territorial boundaries" in order to attract migrating females. We doubt, however, that human females would have visited groups of strange males for any reason unless accompanied by male family members or mates. Miller (2000a) notes that some birds sing in large groups to attract females, suggesting that such groupings may reduce search costs for females. Because human males lived in groups, female search costs would not have been a selection pressure for group singing and dance per se. Further, group singing and dancing among humans is often highly synchronized, an important aspect of these phenomena that has little relevance to female search costs. 


\section{Social Cohesion or Bonding}

Roederer (1984) proposed that music might serve to promote social cohesion, a suggestion that has been echoed by numerous researchers (e.g., Brown 2000; Freeman 1995, 2000; Richman 1987). Evolutionary models strongly suggest that individuals join groups because they are able to gain fitness benefits from group members by providing fitness benefits in return (see, e.g., Axelrod and Dion 1988). Such cooperative strategies commonly take the form of either exchanges of benefits (including inclusive fitness benefits) or mutualism. Group cohesion, then, is a consequence of (1) group members perceiving that they are able to provide valuable benefits to others and that others are able to provide valuable benefits to them and / or (2) group members perceiving that they share important fitness interests with other group members, interests that are most likely to be served by collective action on the part of the group. Group cohesion is thus served by the exchange of credible information among group members regarding valuable benefits they have to offer and/or important interests they share with other group members.

Both music and dance are rich media of communication but they communicate little about the benefits that one can offer in reciprocal exchanges, and they communicate equally little about one's fitness interests and how they overlap with the fitness interests of others. Although musical and dance performances are informative about overall physical ability and health, they are uninformative about particular skills and goals. For example, is Pavarotti a good hunter? What are his political goals? The most potent cause of social cohesion, as countless studies have shown, is an external threat to the group (e.g., LeVine and Campbell 1972). Language is an excellent medium to communicate information about common enemies, establish group goals, and coordinate group actions. Music and dance do not appear to add anything to language's abilities in this regard.

Despite these objections, both the sexual selection hypothesis and the social bonding hypothesis are appealing and seem to capture important aspects of music and dance. We will return to them in the discussion section where we will argue that they can be unified within the broader framework of the coalition signaling hypothesis. Standing against any functional account of human music is the view that it is a byproduct of human adaptations for, e.g., language, auditory scene analysis, emotional calls, habitat selection, and motor control (Pinker 1997). We consider this to be the null hypothesis.

\section{Animal Models}

The functions most commonly ascribed to animal songs are mate attraction, social- or pair-bonding, individual or group recognition, and territorial defense. Despite copious evidence that vocalizations in a wide variety 
of taxa function to defend territories, the possibility that human song functioned to defend territory has been relatively neglected (but see Geissmann 2000; Merker 2000; Slater 2000 for brief comments). There is an enormous literature on individual vocalizations and territorial defense, and a smaller but still substantial literature on coordinated vocalizations and territorial defense. Apes, social carnivores, and many bird species appear to use coordinated vocalizations to warn trespassers that the territory is defended by a dyad or group.

Wickler (1976) argues that among birds, duetting is primarily a signal used by mated pairs in cooperative defense of territory. Hall (2000), for example, found that magpie-lark duets were more threatening territorial signals than solo songs, and that simulated intrusion also caused males and females to approach the speaker together and coordinate more of their vocalizations to form duets. Goth and colleagues (1999) found that both the male song and duet of Megapodius pritchardii (thermometer-birds) functioned mainly in territorial defense. Hughes (1997) found that the loud antiphonal duets of a mated pair of coral-billed ground-cuckoos were often associated with interspecific aggression and could function in territorial defense. She also noted that "Close perching and concurrent duetting by this mated pair may also function in spatial defense since it could advertise a coordinated alliance in territorial defense to potential intruders" (1997: 179).

In a study of Wyoming coyote packs, Gese and Ruff (1998) found that members of resident packs initiated or participated in howling events whereas transient individuals were never observed howling. Coyotes in resident packs howled more frequently than expected along the periphery of the territory than in the core area. The authors conclude that howling by coyotes appears to serve a territorial spacing function that is mainly performed by the alpha pair of the resident pack. Grinnell and McComb (1996) found that groups of female lions roaring in chorus minimize the chances that they will encounter nonresident and therefore potentially infanticidal males. Using playback experiments, they show that "Alien male lions were more reluctant to approach playbacks of three females roaring than of a single female roaring; single males were more reluctant than pairs to approach female roars; and old males were more reluctant than younger males to approach female roars" (1996:55).

Apes, too, appear to coordinate vocalizations and songs to defend territory. Gibbons and siamangs frequently produce protracted and complex songs, often in duets. Kappeler (1984), for example, found that the female song bouts of Moloch gibbons almost certainly functions to defend territory: "In more than ten cases, non-resident gibbons (single animals or pairs) present in the territory of a group reacted to a song bout of the resident female with immediate flight from that area of the forest, without being detected by the residents." Although males in this species did not 
duet with females, they did participate in communal screaming to defend group boundaries against other family groups, and to repel predators. In a study that found support for a social bonding function in duetting siamangs (Hylobates syndactylus) Geissmann (1999) noted that the loudness of the siamang song suggests that territorial advertisement, pair bond advertisement, and (possibly) mate attraction are additional possible functions (see also Geissmann 1986). Finally, Wilson and colleagues (2001) found that in response to the playback of the "pant-hoot" call of a single extragroup male chimpanzee, "Parties with three or more [male chimpanzees] consistently joined in a chorus of loud vocalizations and approached the speaker together. Parties with fewer adult males usually stayed silent, approached the speaker less often, and travelled more slowly if they did approach" (2001:1203). During choruses of pant-hoots, chimpanzees also appear to actively modify their calls to enhance their acoustic similarity (Mitani and Gros-Louis 1998).

We believe that for humans and human ancestors, musical displays may have similarly functioned, in part, to defend territory (and perhaps also to signal group identity), and that these displays may have formed the evolutionary basis for the musical abilities of modern humans. There is, however, an obvious problem with this proposal for modern humans. Musical performances attract, and are greatly enjoyed by, non-group members, precisely the opposite effect desired if music functioned to warn off intruders. The solution to this puzzle can be found in a distinctive feature of human territorial defense: groups commonly enhance their ability to defend their territories by forming alliances with neighboring groups. Territorial defense and alliance formation both require communicating credible information about group capabilities to non-group members, information that would deter intruders but attract allies. We will now outline the hypothesis that music and dance evolved to credibly communicate such information.

\section{SELECTION PRESSURES}

\section{Coalition Quality}

A group of individuals does not, in and of itself, constitute a coalition. Coalition quality, including the very existence of a coalition, has, at a minimum, two important components. The first is a motivation to act collectively to achieve important goals. Allies and enemies need to know how motivated group members are to act collectively both now and into the foreseeable future, a quality we refer to as internal stability. The second important component is an ability to act collectively to achieve important goals. An alliance with a group of individuals that is not internally stable and/or has little ability to act collectively is, in most cases, worthless. 
Considerable theoretical research has demonstrated, furthermore, that the stability of coalitions cannot be assumed. Quite the opposite. Without special mechanisms such as punishment or ostracism, single defections or known endpoints for cooperation can lead to the immediate dissolution of a coalition (e.g., Boyd and Richerson 1992; Gintis 2000).

Coalitions exist because participants realize fitness benefits from their membership in the coalition. The fitness interests of individuals who have associated for long periods of time almost certainly overlap to a considerable degree (e.g., Tooby and Cosmides 1996). Thus, evidence that individuals have chosen to associate and cooperate for a long time is a reliable cue that they will continue to benefit from their association, and thus continue to act as a coalition; it is, therefore, a good index of internal stability. Evidence that individuals are able to coordinate complex physical activities is a good index of an ability to act collectively.

\section{Alliance Formation}

War is ubiquitous in the ethnographic record (e.g., Keeley 1996). In the EEA, a coalition's success in war and other crucial political ventures-and by extension the reproductive success of coalition members-was often predicated on the size and quality of the coalition's allies (e.g., Chagnon 1997; Keeley 1996). Although coalition size was relatively easy to determine, coalition quality was not. Given that alliances are costly to form and maintain, members of coalitions needed to carefully evaluate the benefits that potential allies could have provided. Coalition quality was, arguably, second only to size in importance when evaluating potential allies. Imagine, for example, the following scenario: coalition A has recently relocated to a rich river valley that is inhabited by two coalitions of approximately the same size, $B$ and $C$, who are bitter enemies. Coalition A must decide whether to ally itself with coalition B or coalition C. Because the resulting alliance $\mathrm{A}+\mathrm{B}$ or $\mathrm{A}+\mathrm{C}$ will politically and militarily dominate the river valley, it is in the interests of the members of coalition $B$ and $C$ to impress coalition A with their ability to fulfill their political and military obligations over the long term. It is in the interests of members of coalition A, by contrast, to reliably assess coalition B's and C's ability to provide coalitional benefits, and to provide these benefits over the long term. In addition, it is in all parties' interest that information on quality be communicated relatively quickly. Alliances in contemporary small-scale societies are often formed during feasts which last from days to weeks. Thus, strategies to both signal and detect coalition quality should be able to function in this time frame.

\section{Combat}

Raids are, by far, the most common form of military action in small-scale societies, although battles also occur with some regularity (Keeley 1996). 
In either case, attackers in the EEA needed to assess the ability of their enemies to respond to an attack. As among animals, it was in all the combatants' fitness interests to credibly signal and reliably assess fighting ability prior to an attack (e.g., Rohwer 1982). If the outcome of a fight was clear, the probable losers could withdraw without incurring the costs of a fight. As noted above, coalition size was the best indicator of military power, but coalition quality - the ability of members to execute rapid, highly coordinated actions, and their motivation to act as a coalition-was obviously critical as well. Combatants on both sides would have reaped substantial fitness benefits if they could have credibly signaled and reliably assessed coalition quality. A Cree informant living with the Blackfoot described a battle from his youth in the 1720s, in which his group of 350 warriors came upon a similarly large group of enemy Snake warriors; interestingly, after making a show of numbers but before commencing battle, the enemies sang and danced:

Both parties made a great show of their numbers, and I thought that they were more numerous than ourselves. After some singing and dancing, they sat down on the ground, and placed their large shields before them, which covered them. We did the same... (Tyrell 1916:328-330; quoted in Bamforth 1994).

As we will discuss below, musical displays either on the field of battle or in settlements during times of war could have signaled coalition formidability above-and-beyond coalition size. They could also have signaled coalition size and readiness when visibility was poor (e.g., at night, or in hilly or wooded terrain) and, by coordinating their signaling, could do so over considerable distances (cf. Merker 2000).

Because both alliance formation and warfare are common in the ethnographic and historical record (e.g., Hayden 1996; Keeley 1996), it is plausible that in ancestral environments there was a strong selection pressure on members of coalitions to both signal and assess coalition quality in each of these contexts. ${ }^{2}$

\section{THE ADAPTATION}

\section{Signaling Coalition Quality}

The ideal signal of coalition quality would be one that could be quickly and easily decoded by recipients, but which could only be encoded and/or transmitted by coalitions that were internally stable, likely to remain internally stable, and had the ability to execute complex, coordinated actions. Further, the signal should be able to represent a continuum of past stability. We propose that music and dance are just such signals. Two 
universal features of music and dance, synchronization and variation (e.g., Lerdahl and Jackendoff 1983; Merker 2000), are ideally suited to credibly signal both that a coalition has been internally stable (and, if the past predicts the future, is likely to continue to be internally stable) and that they are able to execute rapid, complex, coordinated action.

All that is required for a signal to be credible is that it be necessarily correlated with the quality that it is supposed to communicate to others (Maynard Smith 2001). Music and dance are credible signals because the time needed to create and practice music and dance necessarily corresponds to a key dimension of the underlying quality of the coalition: the amount of time coalition members have associated with one another. The essence of our proposal is that music and dance take considerable time to compose and to practice. ${ }^{3}$ Each consists of a number of repeated elements that are frequently performed in synchrony with other people (solo performances will be considered briefly below). The repeated elements are often arranged hierarchically and can have a number of variations. Thus, both music and dance compositions can be arbitrarily complex, much like language (see, e.g., Lerdahl and Jackendoff 1983). Members of recently established coalitions would only be able to compose, practice, and thus perform relatively simple, unsophisticated music and dance. Their performances could also suffer from a relative lack of synchrony. Long-established coalitions, in contrast, would have had the time to compose and practice more complex, sophisticated pieces, and their performances would achieve greater degrees of synchrony. A performance of a relatively simple piece of music would signal that a coalition had been internally stable for perhaps only days or weeks, whereas a successful performance of a complex piece of music would credibly signal that a coalition had been internally stable for months or years.

Complex music and dance performances can only be created by coalitions with considerable internal stability, yet these performances can be displayed to, and "decoded" by, allies and enemies in a very short period of time-music is much easier to appreciate than it is to compose or perform. Note that music and dance do not cause social cohesion (as in the social bonding hypothesis); rather, they signal social cohesion (cf. Eibl-Eibesfeldt 1989:695), a cohesion that was obtained by other means. ${ }^{4}$ Music and dance are also, by their very nature, credible signals that the performers are able to execute rapid, coordinated actions. As noted above, rhythm is, among singing primates, unique to humans, and the ability to form non-kin-based cooperative relationships between groups is also unique to humans; we are arguing that the latter would be difficult without the former.

Cross-culturally, music and dance are important aspects of the visits, feasts, and ceremonies that often accompany the formation and mainte- 
nance of alliances, a fact that is central to the coalition signaling hypothesis. Here is one utterly typical example of a visit marked by dancing:

The Copper Eskimos are constantly paying visits to other communities, and every visit of importance is marked by a dance in which the leading members on both sides take part. Every Eskimo, therefore, whether man or woman, can not only sing and dance, but can even in some measure compose dance-songs (Roberts 1925:12).

And here is another from the Columbian Barasana:

Dances at which food is ceremonially exchanged between longhouse communities are called bare ekaria wi, house where food is given. The food exchanged is always forest produce of some kind. Usually it consists of smoked fish or meat, but sometimes caterpillars and pupae, ants, termites, beetle larvae, or pulped mirití or pupunha palm fruit are exchanged, always in large quantities. For these dances, the donors travel to the recipients' house, usually arriving in the late afternoon. They do not enter their hosts' house that night, but sleep in shelters constructed a little distance off. After dark, they dance on the plaza in front of the house and chant there with their hosts. In the morning, they enter the house, carrying in the food amidst a great amount of noise. The food is then ceremonially presented to the hosts and dancing begins. The dancing continues all day and all night, ending at dawn. Exchanges of food are mostly, but not always, between affinally related local groups (Hugh-Jones 1979:34).

\section{LOTS OF PRACTICE MAKES PERFECT}

The coalition quality hypothesis requires that learning and practicing music and dance be an important part of social life in traditional societies. Consistent with this, there is considerable ethnographic evidence that children are both motivated and encouraged to learn the musical repertoire of their group (Merriam 1964:145-158), perhaps even starting at birth (cf. Dissanayake 2000). Mead (quoted in Merriam 1964:160), for example, noted that among the New Guinea Manus:

Whenever there is a dance there is an orchestra of slit drums of all sizes played by the most proficient drummers in the village. The very small boys of four and five settle themselves beside small hollow log ends or pieces of bamboo and drum away indefatigably in time with the orchestra (1930:34).

Among the Venda of the Northern Transvaal, Blacking (quoted in Merriam 1964:148) similarly observed that: 
From the earliest age, Venda children have every opportunity to imitate the songs and dances of adults, as most music is performed publicly and children generally follow their mothers everywhere until at least the age of three. Their efforts to imitate adults and older children are admired and encouraged rather than hushed up, and spectators often comment when a small child begins to clap or jump about in response to music . . . (1957:2).

Extensive rehearsals are also frequently noted in the ethnomusicological literature, both as a means of maintaining and enhancing musical skills and to prepare for important performances (Merriam 1964:159-163). Mooney (quoted in Merriam 1964:159), for example, reported on rehearsals for the Ghost Dance among the Sioux:

The leaders, both men and women, frequently assembled privately in a tipi to rehearse the new or old songs for the next dance.... Rehearsals were held in Black Coyote's tipi almost every night . . . , each session usually lasting about three hours (1896:918).

Thompson (quoted in Merriam 1964:160) similarly observed that in Southern Lau, Fiji:

Meke learning provides entertainment for the whole village. Two or three months before an important event . . . meke are practiced on the ceremonial ground almost every afternoon and, if the moon is bright, in the evening. The dance is repeated innumerable times until each individual has mastered every detail (1940:76).

The importance placed on rehearsals suggests that group members are highly motivated to make a good impression on their guests or hosts.

The coalition quality hypothesis also accounts for musical variety. Because membership in human coalitions is relatively fluid, music could not signal coalition quality if there were only one song-everyone in the population would simply learn the one song, and performance of this song would then reveal nothing about the quality of specific coalitions within the population. Listeners should only attribute quality to coalitions skillfully performing compositions with novel features. There will obviously be an evolutionary arms race between signal senders, who benefit from an increasing ability to master complex pieces rapidly, and signal receivers, who benefit from an increasing ability to discriminate subtle differences in signals that correspond to practice time. Partner selection (e.g., Bull and Rice 1991; Nöe 1992) and coalition selection could have evolutionary effects similar to sexual selection, particularly the effects of sexual selection on musical variety (e.g., Werner and Todd 1997). Musical variety might also enable the reasonably reliable signaling of group identity in situations 
where that was in the group's interest (e.g., territorial defense by a group with a formidable military reputation).

\section{Emotionality: Signaling the Coalition's Strategic Stance}

Group performances are also credible signals of collective interests. If most group members invested time and energy singing and dancing for visitors, the visitors might rightly conclude that the hosting group as a whole was strongly motivated to secure an alliance with them, whereas if only a small fraction of a large group bothered to do so, the visitors could rightly conclude the opposite. This argument has implications for the emotionality of music.

Music can reliably communicate recognizable emotions to listeners, even those listening to music from an unfamiliar tonal system (Balkwill and Thompson 1999). The coalition quality hypothesis provides a natural interpretation of the relationship between music and emotion. Emotions are best thought of as psychological mechanisms that organize other psychological mechanisms to achieve a strategic goal (Cosmides and Tooby 2000). For example, responding to a raid on one's village requires that a variety of psychological mechanisms be activated (e.g., alertness to movement) and others deactivated (e.g., fatigue). The emotion of anger experienced by the victims of the raid orchestrates a host of psychological and physiological adaptations in order to fashion a retaliatory response that, in the EEA, would have increased the victims' fitness. Operating at a superordinate level, emotions are thus strategic in nature. It appears that signaling some emotions like sadness, happiness, and anger to others was adaptive for individual ancestral humans in their rich social interactions with other individuals.

Because humans also have rich social interactions at the group level, it may have been adaptive for groups to signal a collective emotional (i.e., strategic) state to others: for example, that they are all angry, and intend to act together in response to their anger. On this view, music may function as the group-level analog of the signals associated with emotions on the individual level. As Burrows (1945:78; quoted in Merriam 1964:219) writes of the music among the islanders of Uvea and Futuna, "Where an emotion may be either individual or collective, it is the collective aspect that finds expression in song." 5 Thus, both the degree of participation in, and the emotions expressed by, song and dance performances by one group are important cues for other groups.

In a specific example from a hunter-gatherer group that illustrates how the emotional component of music may reflect a strategic stance, most songs and dances performed during the competitive, intercommunity dance contests of the Inupiaq-speaking Eskimo of northern Alaska are 
humorous, perhaps reflecting, in part, "the ancient belief that a smiling visitor cannot be seeking blood-feud vengeance" (Johnston 1980:370). Listeners who sympathize with the emotions expressed in music may respond with similar emotions, much as they do when an individual expresses his or her emotions.

\section{EXPERIMENT}

Using a between-subjects design, we tested two predictions of the coalition signaling hypothesis: (1) that people will infer coalition quality from music quality, and (2) that perceived music quality will depend, in part, on the degree of synchronization of the music (less synchrony predicting lower quality). All data for this pilot study were collected at the University of California, Santa Barbara. Hypotheses vis-à-vis dance will be tested in a future study.

\section{METHODS}

\section{Participants}

Participants were 159 students in several undergraduate anthropology courses. Ages ranged from 18 to $32($ mean $=21.0$, s.d. $=2.35)$, with 68 males and 91 females.

\section{Stimuli}

A song with four parts (acoustic drums, bass guitar, acoustic guitar, electric guitar) was composed for this study by one of the authors (GAB). Each instrument was digitally recorded on a separate track. Three, one-minute versions of the song were then created by mixing the four tracks. In the first version, all four tracks were mixed in synch.

In the second version, each track was delayed by 60 milliseconds (ms) relative to the previous track. That is, the bass entered $60 \mathrm{~ms}$ behind the electric guitar, which entered $60 \mathrm{~ms}$ behind the acoustic guitar, which entered $60 \mathrm{~ms}$ behind the drums. This was the out-of-synch version. A $300 \mathrm{~ms}$ tone recorded on all four tracks simultaneously was used to offset the tracks from one another (Figure 1).

In the final, scrambled version, eight timing "mistakes" were created (two mistakes on each track/instrument). The timing mistakes were $\pm 1-3 \%$ tempo alterations created with the "stretch" function in Cool Edit Pro, a multitrack software package. This function allows users to retain pitch values when making tempo changes. Although each mistake lasted 


\section{Drums}

Acoustic guitar

Electric guitar

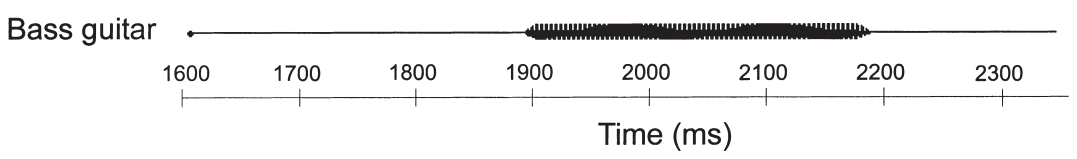

Figure 1. Four instruments were offset $60 \mathrm{~ms}$ from one another using the $300 \mathrm{~ms}$ tone as a cross-track marker. The drums were the anchor track, with the acoustic guitar, electric guitar, and bass guitar offset $60 \mathrm{~ms}, 120 \mathrm{~ms}$, and 180 ms, respectively, for the out-of-synch version.

only two to five seconds, tempo alterations shift the track from that point forward, resulting in varying synchrony between instruments. For example, a 3\% increase (speeding up) in tempo beginning at 00:25 and ending at 00:28 would result in that track being $88 \mathrm{~ms}$ ahead of those without alterations from 00:28 on. Mistakes were placed in a manner that resembles actual occurrences during musical performances in that initial mistakes often result in subsequent immediate mistakes by other performers (Figure 2).

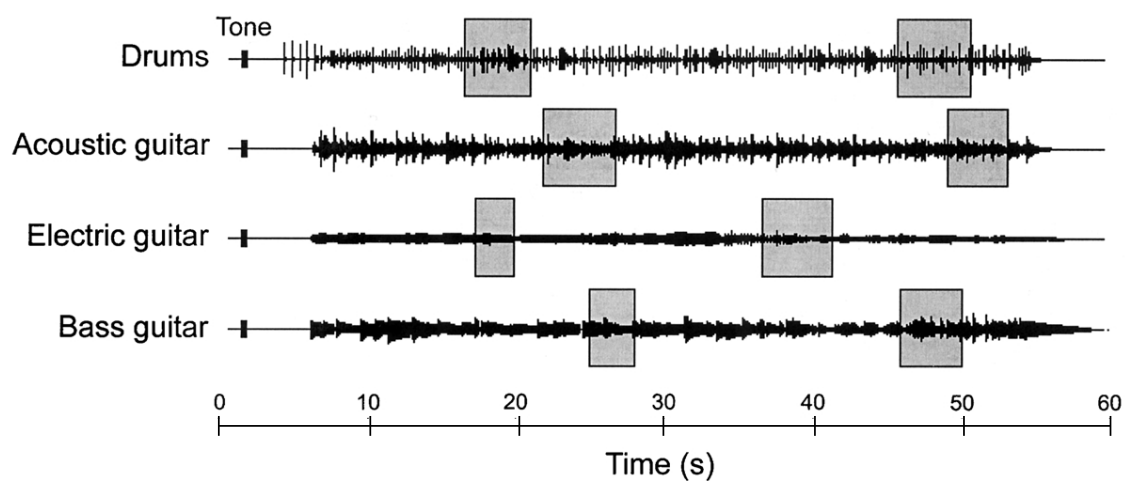

Figure 2. Eight timing alterations (two in each track/instrument) were created for the scrambled version. Shaded regions represent approximate areas where changes were made. 
After mixing, the three versions (minus the $300 \mathrm{~ms}$ tone) were burned onto a CD as three separate tracks. Participants were exposed to one of the three versions. The song was played on a Sony portable stereo.

\section{Measures}

After listening to one version of the song, participants were asked to fill out a brief questionnaire (see Appendix). The questionnaire was designed to assess the participants' perception of music quality, their perception of coalition quality, and their own musical ability. A composite "coalition quality" score was computed by summing items 2-6 of the questionnaire (total scores could range from 5 to 35 ; Cronbach's alpha $=.76$ ). A composite musical quality score was computed by summing items 1,11 , and 12 (total scores could range from 3 to 21; Cronbach's alpha $=.67$ ). Nunnaly (1978) has indicated 0.7 to be an acceptable reliability coefficient (Cronbach's alpha) but lower thresholds are not infrequently used in the literature.

\section{Procedures}

The Kolmogorov-Smirnov test (with the Lilliefors correction) revealed that all of the variables differed significantly from a normal distribution. Because the Kolmogorov-Smirnov test is overly sensitive to deviations from normal (and because standard transformations failed to normalize the variables), we inspected the histograms, normal Q-Q plots, and skew and kurtosis values of all variables. This revealed that the distributions were reasonably normal with little skew or kurtosis. It has long been established that moderate violations of parametric assumptions have little or no effect on substantive conclusions in most instances (e.g., Cohen 1969:266-267), so, when no nonparametric test was available, parametric tests were used (i.e., for multivariate tests). Otherwise, we used nonparametric tests such as Spearman's rank test $\left(r_{s}\right)$ and the Mann-Whitney $U$ test $(Z)$. All $p$-values are one-tailed unless stated otherwise.

\section{RESULTS}

\section{Perceptions of Music Quality vs. Inferences of Coalition Quality}

As predicted, the composite coalition quality score was significantly positively correlated with each of the music quality items, and with the composite score (see Table 1, row 1). (Except for item 5-How likely is it that these men grew up together? - each of the individual components of the coalition quality score was also significantly correlated with each of the music quality items.)

A control item, "How nice do you think these men are?", designed to test the demand characteristics of the study (e.g., do participants perceive 
Table 1. Correlation Coefficients: Comparing (1) the coalition quality score with the music quality items; (2) the niceness score with the music quality items; and (3) the coalition quality score with the music quality score, controlling for the niceness score. Coefficients relate variables across all three versions of the music stimulus.

\begin{tabular}{|c|c|c|c|c|}
\hline & $\begin{array}{l}\text { How much } \\
\text { did you like } \\
\text { this music? }\end{array}$ & $\begin{array}{l}\text { How skilled do } \\
\text { you think these } \\
\text { musicians are? }\end{array}$ & $\begin{array}{l}\text { How much do } \\
\text { you think the } \\
\text { musicians } \\
\text { practiced this } \\
\text { piece of music? }\end{array}$ & $\begin{array}{l}\text { Composite } \\
\text { music } \\
\text { quality score }\end{array}$ \\
\hline $\begin{array}{l}\text { Coalition quality } \\
\text { score }\end{array}$ & $\begin{array}{l}r_{s}=.39 \\
p<.001 \\
n=158\end{array}$ & $\begin{array}{l}r_{s}=.44 \\
p<.001 \\
n=158\end{array}$ & $\begin{array}{l}r_{s}=.46 \\
p<.001 \\
n=158\end{array}$ & $\begin{array}{l}r_{s}=.53 \\
p<.001 \\
n=158\end{array}$ \\
\hline $\begin{array}{l}\text { How nice do you } \\
\text { think these men } \\
\text { are? }\end{array}$ & $\begin{array}{l}r_{s}=.15 \\
p=.064 \\
n=156\end{array}$ & $\begin{array}{l}r_{s}=.35 \\
p<.001 \\
n=156\end{array}$ & $\begin{aligned} r_{s} & =.071 \\
p & =.38 \\
n & =156\end{aligned}$ & $\begin{array}{l}r_{s}=.23 \\
p=.002 \\
n=156\end{array}$ \\
\hline $\begin{array}{l}\text { Coalition quality } \\
\text { score, control- } \\
\text { ling for niceness }\end{array}$ & $\begin{array}{l}r=.34 \\
p<.001 \\
n=153\end{array}$ & $\begin{array}{l}r=.27 \\
p<.001 \\
n=153\end{array}$ & $\begin{array}{l}r=.47 \\
p<.001 \\
n=153\end{array}$ & $\begin{array}{l}r=.48 \\
p<.001 \\
n=153\end{array}$ \\
\hline
\end{tabular}

that "good things" are expected to correlate with "good things"?), did in fact correlate significantly positively with one music quality item, and not quite significantly with another (two-tailed; see Table 1, row 2). The "niceness" item also correlated with the coalition quality score $\left(r_{s}=.33, p<.001\right.$, $n=156)$. To determine whether the correlation of the coalition quality score with the music quality items was an artifact of their correlation with the perception that the musicians were nice, the correlation matrix in Table 1, row 1 was recomputed controlling for the niceness score. There was little change in the coefficients (Table 1, row 3 ).

Self-reported musical experience was not correlated with either perceptions of music quality $\left(r_{s}=-.014, p=.86, n=159\right)$ or coalition quality $\left(r_{s}=\right.$ $-.026, p=.75, n=158)$. Self-reported musical experience also had no effect on the relationship between perceptions of music quality and coalition quality: the Pearson's $r$ between the music quality score and the coalition quality score was $r=.50(p<.001, n=158)$. After controlling for selfreported musical experience, the partial correlation was $r=.50(p<.001$, $n=155)$.

Age was significantly negatively correlated with both perceptions of music quality $\left(r_{s}=-.26, p=.001, n=159\right)$ and coalition quality $\left(r_{s}=-.21\right.$, $p=.009, n=158)$. Controlling for age, the correlation between music quality and coalition quality remained essentially unchanged $(r=.48, p<.001$, $n=155$ ). Females reported significantly higher music quality scores than did males (females: mean $=13.6$, s.d. $=3.20, n=91$; males: mean $=12.6$, s.d. 
$=2.88, n=68 ; Z=-2.34, p=.01, n=159)$ but there was no significant sex difference in reported coalition quality scores (females: mean $=21.0$, s.d. $=$ 4.20, $n=90$; males: mean $=21.0$, s.d. $=4.71, n=68 ; Z=-0.060, p=.95, n=$ 158).

\section{Perceptions of Music Quality vs. Manipulated Music Quality}

In order to test whether the degree of synchrony of the performers in the music stimuli affected perceptions of music quality, the composite music quality score was compared across versions of the stimulus. As predicted, the stimulus version in which each track was delayed by $60 \mathrm{~ms}$ relative to the previous track was perceived to be of significantly poorer quality than the "in-synch" version (in-synch: mean $=14.5$, s.d. $=2.64, n=42$; outof-synch: mean $=12.4$, s.d. $=2.82, n=95 ; Z=-3.83, p<.001, n=137$ ); the "scrambled" version, however, was not perceived to be of significantly poorer quality (mean $=13.8$, s.d. $=4.09, n=22 ; Z=-0.40, p=.35, n=64)$, contrary to predictions. (This result may be due to the small number of participants in this condition; the mean music quality score for the scrambled condition was intermediate between the in-synch and out-of-synch conditions. Data were collected by EHH, who has since changed institutions, unfortunately precluding the collection of additional data.)

Self-reported musical experience did not modify the relationship between degree of synchrony (i.e., 0 vs. $60 \mathrm{~ms}$ delay) and perception of music quality. A measure of effect size of degree of synchrony as a predictor of perceived music quality in a univariate GLM was $\eta^{2}=.112\left(\eta^{2}\right.$ is analogous to $r^{2}$ ). Adding self-reported musical experience to the model as a covariate did not significantly change this effect size: $\eta^{2}=.115$. As noted above, there was a significant negative relationship between age and perceived music quality. Adding age to the univariate GLM model as a covariate slightly reduced $\eta^{2}$ from .112 to .089 .

Also as noted above, there was a significant sex difference in perceived music quality. Examining the impact of sex on perceived music quality separately for the in-synch and out-of-synch conditions revealed that women reported significantly higher music quality than men in the insynch condition (females: mean $=15.4$, s.d. $=2.39, n=28$; males: mean $=$ 12.9 , s.d. $=2.38, n=14 ; Z=-2.97, p=.002$, two-tailed, $n=42$ ), but not in the out-of-synch condition (females: mean $=12.8$, s.d. $=2.97, n=50$; males: mean $=12.0$, s.d. $=2.60, n=45 ; Z=-1.44, p=.15$, two-tailed, $n=95)$ nor in the scrambled condition (females: mean $=13.0$, s.d. $=4.24, n=13$; males: mean $=15.0$, s.d. $=3.77, n=9 ; Z=-1.32, p=.21$, two-tailed, $n=22$ ).

\section{Perceptions of Coalition Quality vs. Manipulated Music Quality}

Although we did not predict a direct effect of synchrony on perceived coalition quality, coalition quality was nonetheless perceived to be signifi- 
cantly less in the $60 \mathrm{~ms}$ condition compared with the "in-synch" condition (in-synch: mean $=21.9$, s.d. $=3.98, n=41$; out-of-synch: mean $=20.7$, s.d. $=$ $4.29, n=95 ; Z=-2.04, p=.020, n=136)$, but not in the "scrambled" condition (mean $=20.5$, s.d. $=5.55, n=22 ; Z=-0.94, p=.17, n=63$ ). We did predict that synchrony would affect perceived music quality, which, in turn, would affect perceived coalition quality. We computed the standardized path coefficients for this model (Figure 3), which supported our predictions.

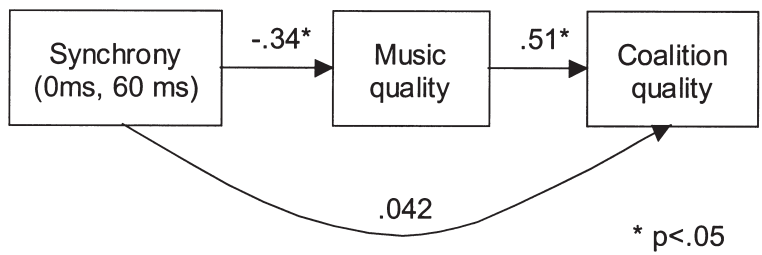

Figure 3. Standardized path coefficients. Increased delay between tracks caused perceptions of music quality to decrease. Perceptions of decreased music quality were correlated with perceptions of decreased coalition quality. With music quality in the model, there was no direct effect of synchrony on perceptions of coalition quality.

\section{LIMITATIONS}

This study has two principal limitations. First was our inability to strictly control the auditory environment of participants. Participants listened to the music in small classrooms. Some students were sitting in front, and some in back (the portable CD player was placed in the front of the classroom). In addition, the three conditions of the test were distributed across a half-dozen different rooms. We kept the player volume control at a fixed position for all tests, but perceived volume and other qualities of the music could have differed in ways that affected our results.

Second, the demand characteristics of the study were poor-positive music qualities were expected to correlate with positive personal and social qualities, and participants may have realized this. We are somewhat encouraged that the "niceness" score correlated significantly with only one music quality item, and not quite significantly with another (whereas the coalition quality score correlated highly significantly with all three); we are also encouraged that the correlations of coalition quality with music quality remained strong after controlling for the "niceness" score. Nonetheless, we hope to improve the demand characteristics of future studies. 


\section{DISCUSSION}

As predicted, perceptions of music quality were positively correlated with perceptions of coalition quality. Also as predicted, music with degraded synchrony, a dimension of music quality that is theoretically significant for the coalition quality hypothesis, was perceived to be of lower quality, and the coalition quality of the performers was also perceived to be lower. These results offer provisional support for the coalition quality hypothesis. These results were only seen for the version of the stimulus in which tracks were mixed a constant $60 \mathrm{~ms}$ out of synch. There was no such effect for the version in which individual tracks were alternately delayed and advanced relative to other tracks, perhaps owing to the small sample of participants.

\section{Unifying the Coalition Signaling and Sexual Selection Hypotheses}

The coalition quality hypothesis does not account for solo performances, but the sexual selection hypothesis can account for many cases. We offer the following synthesis of these two hypotheses for music and dance function. Alliances between coalitions in small-scale societies are frequently solidified by marriage. During alliance formation, individuals must not only assess coalition quality, they must also assess the mate quality of their potential allies, since these allies will also be the husbands and wives of their sons and daughters (or themselves). Consequently, whereas some musical and dance performances may be designed to signal coalition quality alone, others may be designed to "showcase" high-quality mates to potential allies. Belonging to a large and high-quality coalition probably is, in itself, an important component of mate value (see, e.g., Draper and Hames 2000, and references therein, on sibship size and fertility). By signaling coalition quality, coalition members are simultaneously signaling an exogenous aspect of their mate value. Some music and dance might be composed to highlight the fact that particular members are well-regarded members of the coalition, perhaps by assigning them solo parts that alternate with, or are backed up by, the singing and dancing of other coalition members. The willingness of the coalition to showcase one of its members would have been a reliable indicator that this member was well regarded by the coalition. Conversely, a potential mate's ability to perform the group's songs and dances was a reasonably reliable cue that he or she was indeed a member of the coalition. What a disaster it would have been to attempt to form an alliance by marriage, only to discover later that bride or bridegroom was not, in fact, a member of the coalition! ${ }^{6}$ The mate qualities that are reliably signaled by music and dance-e.g., health, nutrition, proper development, endurance, creativity_are also important qualities for allies. Finally, singing appears to have more than one function in some animal species. 
We did find a sex difference in perceptions of music quality. Female undergraduate participants rated the "in-synch" stimulus quality higher than male participants, perhaps because the performers of the music stimulus were male. Music and dance appear to be designed to signal the quality of both individuals and groups, as this Andaman Island example, first published by Man in 1885, nicely illustrates:

[L]arge gatherings of a tribe are also organised from time to time by the head chief, who generally receives an offer, in the first instance, from the members of some far-off community to give a jeg- at his encampment. As these offers are only made when it is known to be convenient they are always accepted, and invitations for a certain day are at once sent to all living within an easy distance. The intervening days are spent by the proposers of the entertainment in perfecting a song and chorus, which it is intended to perform, and which generally has been composed expressly for the occasion, by some volunteer upon whom also devolves the responsibility of singing the solo and training the so-called chorus. As a considerable amount of distinction among his fellows may be gained by the manner in which he aequits himself in his onerous undertaking, it will be readily understood that the improvisatore spares no pains over the preparation and rehearsal of a new song, which, as he fondly hopes, will render his name, if not immortal, at all events famous for many a year. The subject is chosen in reference to some recent personal or tribal exploit or adventure, and is embodied in a distich, followed by a chorus, or rather refrain, which as often as not consists merely in a repetition of the couplet forming the solo; in this refrain women alone are instructed; the main point aimed at is apparently accuracy of time, for, as I have said in my last paper, everything, even sense, is sacrificed in their songs to rhythm....

During the solo, which partakes of the character of a "recitative," all other voices are hushed, and the listeners remain motionless, but as soon as the signal is given for the refrain, a number of men emerge suddenly from the gloom surrounding the encampment, and rushing excitedly into the arena, perform their part with frantic energy, generally adding their voices to those of the women to swell the volume of sound (Man 1932:168-170).

\section{Within-Group Functions of the Coalition Signaling System}

A connection also exists between the coalition quality hypothesis and the "social cohesion" hypothesis of music function. Although we are proposing that music and dance signal social cohesion rather than cause or promote social cohesion, members of coalitions who perceive that continued membership in the coalition will yield significant benefits should be motivated to practice singing and dancing together. Coalition members should enjoy singing and dancing, even when other coalitions are not present, because they need to develop and master their musical repertoire. Further, once individuals have demonstrated, by other means, their ability 
to provide valuable benefits or that they share important interests with other group members, their subsequent costly effort to master a group's musical repertoire is a credible signal of their loyalty to the group because it significantly increases the costs of switching groups, enhancing group stability (Dawkins 1976; Maynard Smith 1977; Wickler 1980). There is some empirical evidence supporting this hypothesis. Anshel and Kipper (1988) found that group singing of popular songs enhanced trust and cooperation among adult men.

We propose one additional within-group function of music. Work songs are ubiquitous in the ethnographic record (Merriam 1964:217). By singing in unison, coalition members can signal to absent members that a collective action is taking place (both encouraging them to join, and ensuring that due credit is given for group contributions). If this is also a function of music, it might explain some ritual uses of music, such as summoning the help of a spirit. The following example illustrates this possibility, as well as the possibility that, consistent with the coalition quality signaling hypothesis, music and dance performances may induce powerful spirit allies to visit:

[The Plains Indians'] Sun dance is performed to call the thunderbird to bring rain and thus provide grass for the buffalo (or, today, cattle and crops), and to induce this rainmaker to stop and "rest" in their territory where a "nest" is provided for him in the fork of the Sun dance pole (Howard and Kurath 1959:2; quoted in Merriam 1964:235).

"War dances" could also repel unwanted spirits. By combining singing with other group activities, group members can also reduce the time costs associated with practicing. Finally, individuals who practice singing and dancing together may improve their ability to coordinate action in other arenas.

\section{CONCLUSION}

The only sure conclusion of more than a century of anthropological inquiry into music and dance is succinctly captured in a Pueblo Indian's remark to Leslie White: "My friend, without songs you cannot do anything" (White 1962:115; quoted in Merriam 1964:225). Musical performances permeate virtually every aspect of social life. Although we do not believe we have explained every use of music or dance, we hope that our coalition signaling hypothesis will help to advance the debate on the evolution of these important components of culture by suggesting why music and dance are performed in groups, why they express and arouse emotions, why they are 
often associated with routine activities of the group, why they frequently appear in ritual, and why musically talented individuals are often supported and encouraged by other group members, including group leaders.

Many recent models of cooperation emphasize individuals signaling quality of some sort to group members (e.g., Alexander 1987; Boone 1998; Gurven et al. 2000; Hawkes et al. 2001; Leimar and Hammerstein 2001; Nowak and Sigmund 1998; Smith and Bliege Bird 2000; Sosis 2000; Sugiyama and Chacon 2000). Given the ubiquity of feasting and alliancemaking in the ethnographic record, our hypothesis suggests that such "showoffs" may, in part, be demonstrating their ability to contribute to coalition quality, or, as in the Andaman Islander example, their ability to improve coalition signaling itself. The payoff for the individual would be the improved quality of their coalition and, more importantly, obtaining an increased leadership role (and thus the ability to influence group actions); the payoff for group members would be increased coalition success in forming alliances and competing with other groups. Our hypothesis also suggests that the above models may also have some applicability to signaling by groups to other groups. ${ }^{7}$

Our hypothesis has obvious implications for the evolution of psychological adaptations underlying cultural production in other domains that are important for attracting allies (and embarrassing enemies); just as complex musical and dance performances may impress allies, so, too, may elaborate meals, high-quality tools and artifacts, fancy clothes, entertaining and informative stories, and impressive body decorations (cf. Hayden 1990, 1996; Mauss 1967). Finally, the imitative abilities necessary to learn songs and dances may have provided, in part, pre-adaptations for cultural transmission in other domains.

We thank Silke Atmaca, Roberto Fernandez Galan, Peter Hammerstein, Nicole Hess, Eva Koernicke, June-el Piper, Aaron Sell, Francis Steen, Don Symons, Arndt Telschow, J. Anderson Thomson, Peter Todd, members of the Institute for Theoretical Biology, and three anonymous reviewers for informative comments on the ideas presented here.

Edward Hagen is a research scientist at the Institute for Theoretical Biology, Humboldt University, Berlin. Gregory Bryant is a doctoral candidate in the Department of Psychology, University of California, Santa Cruz.

\section{NOTES}

1. Payment for instruction or rights to a song is also common; this is consistent with both the sexual selection hypothesis and the coalition signaling hypothesis. 
2. Unlike, e.g., Hayden 1996, we are not focusing on competitive feasting such as potlatches, but simply on the singing, dancing, and food preparation that usually accompany visits by allies and potential allies and also accompany marriages, etc.

3. Although it might seem obvious to invoke costly signaling theory (Spence 1974; Zahavi 1975), in our theory it is not the costs of music and dance that are important per se, but rather the necessary correlation between practice time and the time group members have associated with one another (and thus the internal stability of the coalition).

4. Knight (1991), in his "sex-strike" hypothesis, has proposed that rituals (which can include music and dance) evolved so that women could signal that they were, as a group, withholding sex from all men in the group in order to coerce men to provide resources like meat. Although we have reservations about the plausibility of this scenario, it is nevertheless an alternative view of the evolution of ritual as a means to express coalitional solidarity.

5. We are not claiming that, in practice, music never expresses individual emotions, only that it may have evolved, in part, to express collective emotions.

6. It may also have been in the interests of coalition members to prevent nonmembers from easily mimicking the coalition's songs and dances (thereby hindering them from claiming to be a member of the coalition). This may have been an additional selection pressure on the motivation to master complex compositions that could not easily be learned by outsiders.

7. We would emphasize the credibility of the signals, however, and not the costs per se.

\section{APPENDIX}

\section{Page 1: Survey Information and Instructions}

You have been asked to participate as a subject in a study that is part of a research project entitled "Student impressions of music." You will listen to a recording of four men playing a piece of music for one minute. You will then be asked to answer 12 brief questions on page 2 of this form. Please do not turn the page until the music has finished playing. Also, please make no comments until all these forms have been collected at the end of the experiment.

\section{Page 2}

You have just heard 4 men performing a piece of music. Please answer each of the following questions by circling one number:

1. How much did you like this music?

$\begin{array}{lrlllcr}1 & 2 & 3 & 4 & 5 & 6 & 7 \\ \text { Not at all } & & & & \text { Very much }\end{array}$

2. How long do you think these men have known each other?

$\begin{array}{lrrrrrr}1 & 2 & 3 & 4 & 5 & 6 & 7 \\ \text { A very short time } & & & \text { A very long time }\end{array}$


3. How much do you think these men like each other?
1 Very little
34
5
6
7
Very much

4. How willing do you think these men are to help each other?
2
Very little
4
5
6
7
Very much

5. How likely is it that these men grew up together?
1
2
3
4
5 7
Very unlikely
Very likely

6. How likely is it that these men will be friends 5 years from now?
2
34
5
67
Very unlikely
Very likely

1

7. How nice do you think these men are?

$\begin{array}{llllll}1 & 2 & 3 & 4 & 5 & 6\end{array}$

8. What is your age?

9. What is your sex? (circle one) Male Female

10. How experienced are you at singing or playing a musical instrument?

$\begin{array}{lrlllllr}1 & 2 & 3 & 4 & 5 & 6 & 7 \\ \text { Not at all } & & & & & \text { Very }\end{array}$

11. How skilled do you think these musicians are?

$\begin{array}{lrlllllr}1 & 2 & 3 & 4 & 5 & 6 & 7 \\ \text { Not at all } & & & & & \text { Very }\end{array}$

12. How much do you think the musicians practiced this piece of music?

$\begin{array}{lrlllr}1 & 2 & 3 & 4 & 5 & \begin{array}{c}6 \\ \text { Extensively }\end{array} \\ \text { Not at all } & & & & \end{array}$

\section{REFERENCES}

Anshel, A., and D. A. Kipper

1988 The Influence of Group Singing on Trust and Cooperation. Journal of Music Therapy 25:145-155.

Alexander, R. D.

1987 The Biology of Moral Systems. New York: Aldine de Gruyter.

Axelrod, R., and D. Dion

1988 The Further Evolution of Cooperation. Science 242:1385-1390.

Ayotte J., I. Peretz, and K. Hyde

2002 Congenital Amusia: A Group Study of Adults Afflicted with a MusicSpecific Disorder. Brain 125:238-251.

Balkwill, L., and W. F. Thompson

1999 A Cross-Cultural Investigation of the Perception of Emotion in Music:

Psychophysical and Cultural Cues. Music Perception 17:43-64. 
Bamforth, D. B.

1994 Indigenous People, Indigenous Violence: Precontact Warfare on the North American Great Plains. Man (n.s.) 29:95-115.

Blacking, J.

1957 The Role of Music amongst the Venda of the Northern Transvaal. Johannesburg: International Library of African Music.

Boone, J. L.

1998 The Evolution of Magnanimity: When Is It Better To Give Than To Receive? Human Nature 9:1-21.

Boyd, R., and P. J. Richerson

1992 Punishment Allows the Evolution of Cooperation (or Anything Else) in Sizable Groups. Ethology and Sociobiology 13:171-195.

Brown, $\mathrm{S}$.

2000 The "Musilanguage" Model of Music Evolution. In The Origins of Music, N. L. Wallin, B. Merker, and S. Brown, eds. Pp. 271-300. Cambridge: MIT Press.

Bull, J. J., and W. R. Rice

1991 Distinguishing Mechanisms for the Evolution of Cooperation. Journal of Theoretical Biology 149:63-74.

Burrows, E. G.

1945 Songs of Uvea and Futuna. Honolulu: Bernice P. Bishop Museum Bulletin 183.

Catchpole, C. K., and P. J. B. Slater

1995 Birdsong: Biological Themes and Variations. Cambridge: Cambridge University Press.

Chagnon, N.

1997 Yanomamö, fifth ed. New York: Harcourt, Brace, Jovanovich.

Cheney, D. L.

1987 Interactions and Relationships between Groups. In Primate Societies, B. B. Smuts, D. L. Cheney, R. M. Seyfarth, R. W. Wrangham, and T. T. Struhsaker, eds. Pp. 267-281. Chicago: University of Chicago Press.

Cohen, J.

1969 Statistical Power Analysis for the Behavioral Sciences. New York: Academic Press.

Cosmides, L.

1989 The Logic of Social Exchange: Has Natural Selection Shaped How Humans Reason? Studies with the Wason Selection Task. Cognition 31:187-276.

Cosmides, L., and J. Tooby

2000 Evolutionary Psychology and the Emotions. In Handbook of Emotions, second ed., M. Lewis and J. M. Haviland-Jones, eds. Pp. 91-115. New York: Guilford.

Daniel, H. J., K. F. O'Brien, R. B. McCabe, and V. E. Quinter

1985 Values in Mate Selection: A 1984 Campus Survey. College Student Journal 19:44-50.

Darwin, C.

1871 The Descent of Man and Selection in Relation to Sex. London: John Murray. 
Dawkins, R.

1976 The Selfish Gene. London: Oxford University Press.

Denig, E. T.

1930 Indian Tribes of the Upper Missouri. Washington, D.C.: Government Printing Office.

Dissanayake, E.

2000 Antecedents of the Temporal Arts in Early Mother-Infant Interaction. In

The Origins of Music, N. L. Wallin, B. Merker, and S. Brown, eds. Pp. 389-410.

Cambridge: MIT Press.

Draper, P., and R. Hames

2000 Birth Order, Sibling Investment, and Fertility among the Ju/'hoansi

(!Kung). Human Nature 11:117-156.

Eibl-Eibesfeldt, I.

1989 Human Ethology. New York: Aldine de Gruyter.

Freeman, W.

1995 Societies of Brains: A Study in the Neuroscience of Love and Hate. Hillsdale, New Jersey: Erlbaum.

2000 A Neurobiological Role of Music in Social Bonding. In The Origins of Music, N. L. Wallin, B. Merker, and S. Brown, eds. Pp. 411-424. Cambridge: MIT Press.

Geissmann, T.

1986 Mate Change Enhances Duetting Activity in the Siamang Gibbon (Hylobates syndactylus). Behaviour 96:17-27.

1999 Duet Songs of the Siamang, Hylobates syndactylus, II: Testing the Pair-

Bonding Hypothesis during a Partner Exchange. Behaviour 136:1005-1039.

2000 Gibbon Songs and Human Music in an Evolutionary Perspective. In The

Origins of Music, N. L. Wallin, B. Merker, and S. Brown, eds. Pp. 103-123. Cambridge: MIT Press.

Gese, E. M., and R. L. Ruff

1998 Howling by Coyotes (Canis latrans): Variation among Social Classes, Seasons, and Pack Sizes. Canadian Journal of Zoology 76:1037-1043.

Gintis, H.

2000 Strong Reciprocity and Human Sociality. Journal of Theoretical Biology 206:169-179.

Goth, A., U. Vogel, and E. Curio

1999 The Acoustic Communication of the Polynesian Megapode Megapodius pritchardii G. R. Gray. Zoologische Verhandelingen (Leiden) (327):37-51.

Grinnell, J., and K. McComb

1996 Maternal Grouping as a Defense against Infanticide by Males: Evidence from Field Playback Experiments on African Lions. Behavioral Ecology 7:55-59.

Gurven M., W. Allen-Arave, K. Hill, and M. Hurtado

2000 "It's a Wonderful Life": Signaling Generosity among the Ache of Paraguay. Evolution and Human Behavior 21:263-282.

Hall, M. L.

2000 The Function of Duetting in Magpie-larks: Conflict, Cooperation, or Commitment? Animal Behaviour 60:667-677. 
Hawkes, K., J. F. O'Connell, and N. G. Blurton-Jones

2001 Hadza Meat Sharing. Evolution and Human Behavior 22:113-142.

Hayden, B.

1990 Nimrods, Piscators, Pluckers and Planters: The Emergence of Food Production. Journal of Anthropological Archaeology 9:31-69.

1996 Feasting in Prehistoric and Traditional Societies. In Food and the Status

Quest, P. Wiessner and W. Schiefenhovel, eds. Pp. 127-147. Providence: Berghahn Books.

Howard, J. H., and G. P. Kurath

1959 Ponca Dances, Ceremonies and Music. Ethnomusicology 3:1-14.

Hughes, J. M.

1997 Vocal Duetting by a Mated Pair of Coral-Billed Ground-cuckoos (Carpococcyx renauldi) at the Metro Toronto Zoo. Zoo Biology 16:179-186.

Hughes, S. M., M. A. Harrison, and G. A. Gallup

2002 The Sound of Symmetry: Voice as a Marker of Developmental Instability.

Evolution and Human Behavior 23:173-180.

Hugh-Jones, S.

1979 The Palm and the Pleiades: Initiation and Cosmology in Northwest Amazonia.

Cambridge: Cambridge University Press.

Johnsrude, I. J., V. B. Penhune, and R. J. Zatorre

2000 Functional Specificity in Right Human Auditory Cortex for Perceiving Pitch Direction. Brain 123:155-163.

Johnston, T. F.

1980 Alaskan Eskimo Music and Dance. Current Anthropology 21:370-371.

Kappeler, M.

1984 Vocal Bouts and Territorial Maintenance in the Moloch Gibbon. In The Lesser Apes: Evolutionary and Behavioural Biology, H. Preuschoft et al., eds. Pp. 376-389. Edinburgh: Edinburgh University Press. (Reproduced at http:// www.markuskappeler.ch/gib/gibs/vocalbouts.html)

Keeley, L. H.

1996 War before Civilization. Oxford: Oxford University Press.

Knight, C.

1991 Blood Relations: Menstruation and the Origins of Culture. New Haven: Yale University Press.

Leimar, O., and P. Hammerstein

2001 Evolution of Cooperation through Indirect Reciprocity. Proceedings of the Royal Society of London B 268:745-753.

Lerdahl, F., and R. Jackendoff

1983 A Generative Theory of Tonal Music. Cambridge: MIT Press.

LeVine, R. A., and D. T. Campbell

1972 Ethnocentrism: Theories of Conflict, Ethnic Attitudes, and Group Behavior. John Wiley \& Sons.

Man, E. H.

1932 On the Aboriginal Inhabitants of the Andaman Islands. London: Royal Anthropological Institute of Great Britain and Ireland.

Malinowski, B.

1925 Complex and Myth in Mother-Right. Psyche 5:194-216. 
Mauss, M.

1967 The Gift: Forms and Functions of Exchange in Archaic Societies. New York: Norton.

Maynard Smith, J.

1977 Parental Investment: A Prospective Analysis. Animal Behavior 25:1-9.

2001 The Evolution of Animal Signals. Paper presented at the annual meeting of the Human Behavior and Evolution Society, University College, London.

Mead, $\mathrm{M}$.

1930 Growing up in New Guinea. New York: Mentor.

Merriam, A. P.

1964 The Anthropology of Music. Evanston, Illinois: Northwestern University Press.

Merker, B.

2000 Synchronous Chorusing and Human Origins. In The Origins of Music,

N. L. Wallin, B. Merker, and S. Brown, eds. Pp. 315-327. Cambridge: MIT Press. Miller, G.

2000a Evolution of Human Music through Sexual Selection. In The Origins of Music, N. L. Wallin, B. Merker, and S. Brown, eds. Pp. 271-300. Cambridge: MIT Press.

2000b The Mating Mind: How Sexual Choice Shaped Human Nature. New York: Doubleday.

Miller, J.

1997 Military Bands, Marching Off to Glory, Armed with Electric Guitars. New York Times, October 28.

Mitani, J. C., and J. Gros-Louis

1998 Chorusing and Call Convergence in Chimpanzees: Tests of Three Hypotheses. Behaviour 135:1041-1064.

Mooney, J.

1896 The Ghost-Dance Religion and the Sioux Outbreak of 1890. Fourteenth Annual Report of the Bureau of American Ethnology, Pt. 2. Washington, D.C.

Nöe, R.

1992 Alliance Formation among Male Baboons: Shopping for Profitable Partners. In Coalitions and Alliances in Humans and other Animals, A. H. Harcourt and F. B. M. de Waal, eds. Pp. 285-321. Oxford: Oxford University Press.

Nowak, M. A., and K. Sigmund

1998 Evolution of Indirect Reciprocity by Image Scoring. Nature 393:573-577.

Nunnaly, J.

1978 Psychometric Theory. New York: McGraw-Hill.

Peretz, I.

1996 Can We Lose Memory for Music? The Case of Music Agnosia in a Nonmusician. Journal of Cognitive Neurosciences 8:481-496.

Peretz, I., and J. Morais

1993 Specificity for Music. In Handbook of Neuropsychology, vol. 8, F. Boller and J. Grafman, eds. Pp. 373-390. New York: Elsevier.

Perry, D. W., R. J. Zatorre, M. Petrides, B. Alivisatos, E. Meyer, and A. C. Evans 1999 Localization of Cerebral Activity during Simple Singing. NeuroReport 10:3979-3984. 
Pinker, S.

1997 How the Mind Works. New York: W. W. Norton.

Richman, B.

1987 Rhythm and Melody in Gelada Vocal Exchanges. Primates 28:199-223.

Roberts, H. H.

1925 Eskimo Songs: Songs of the Copper Eskimo (Southern Party, 1913-16). Ottawa,

Ontario: F. A. Acland.

Rodseth, L., R. W. Wrangham, A. M. Harrigan, and B. B. Smuts

1991 The Human Community as a Primate Society. Current Anthropology 32: 221-254.

Roederer, J.

1984 The Search for a Survival Value of Music. Music Perception 1:350-356.

Rohwer, S.

1982 The Evolution of Reliable and Unreliable Badges of Fighting Ability.

American Zoologist 22:531-546.

Slater, P. J. B.

2000 Birdsong Repertoires: Their Origins and Use. In The Origins of Music,

N. L. Wallin, B. Merker, and S. Brown, eds. Pp. 49-63. Cambridge: MIT Press.

Smith, E. A., and R. L. Bliege Bird

2000 Turtle Hunting and Tombstone Opening: Public Generosity as Costly Sig-

naling. Evolution and Human Behavior 21:245-261.

Sosis, R.

2000 Costly Signaling and Torch Fishing on Ifaluk Atoll. Evolution and Human Behavior 21:223-244.

Spence, $\mathrm{M}$.

1974 Market Signaling. Cambridge: Harvard University Press.

Sugiyama, L. S., and R. Chacon

2000 Effects of Illness and Injury among the Yora and Shiwiar: Pathology Risk as Adaptive Problem. In Adaptation and Human Behavior: An Anthropological Perspective, N. A. Chagnon, L. Cronk, and W. Irons, eds. Pp. 371-395. New York: Aldine de Gruyter.

Thompson, L.

1940 Southern Lau, Fiji: An Ethnography. Honolulu: Bernice P. Bishop Museum Bulletin 162.

Tooby, J., and L. Cosmides

1996 Friendship and the Banker's Paradox: Other Pathways to the Evolution of Adaptations for Altruism. In Evolution of Social Behaviour Patterns in Primates and Man, W. G. Runciman, J. M. Smith, and R. I. M. Dunbar, eds. Pp. 119-143. Tyrell, J.

Proceedings of the British Academy 88. Oxford: Oxford University Press.

1916 David Thompson's Narrative of His Explorations in Western America, 17841812. Toronto: Champlain Society Publication 21.

Werner, G. M., and P. M. Todd

1997 Too Many Love Songs: Sexual Selection and the Evolution of Communication. In Fourth European Conference on Artificial Life, P. Husbands and I. Harvey, eds. Pp. 434-443. Cambridge: MIT Press/Bradford Books. 
White, L. A.

1962 The Pueblo of Sia, New Mexico. Washington, D.C.: Bureau of American Ethnology Bulletin 184.

Wickler W.

1976 Duetting Songs in Birds: Biological Significance of Stationary and Nonstationary Processes. Journal of Theoretical Biology 61:493-497.

1980 Vocal Duetting and the Pairbond, I: Coyness and Partner Commitment. A Hypothesis. Zeitschrift für Tierpsychologie 52:201-209.

Wilson, M. L., M. D. Hauser, and R. W. Wrangham

2001 Does Participation in Intergroup Conflict Depend on Numerical Assessment, Range Location, or Rank for Wild Chimpanzees? Animal Behaviour 61: 1203-1216.

Zahavi, A.

1975 Mate Selection: A Selection for a Handicap. Journal of Theoretical Biology 53:205-214. 
